University Heart Journal

Vol. 16, No. 1, January 2020

\title{
Coronary Microvascular Dysfunction: An Update
}

\section{SM MUSTAFA ZAMAN, HARISUL HOQUE, KHURSHED AHMED, MD. MUKHLESUR RAHMAN, MSI TIPU CHOWDHURY, MD. ABU JAMIL, MD. FAKHRUL ISLAM KHALED}

Department of Cardiology, Bangabandhu Sheikh Mujib Medical University, Dhaka, Bangladesh.

Address of Correspondence: Prof. Dr. SM Mustafa Zaman, Professor of Interventional Cardiology, Department of Cardiology, Bangabandhu Sheikh Mujib Medical University (BSMMU), Dhaka, Bangladesh. Email:drsmmzaman@yahoo.com

\begin{abstract}
:
Structural and functional abnormalities of the microcirculation can impair myocardial perfusion which is called coronary microvascular dysfunction and the resulting ischemia is known as microvascular ischaemia. Most of the researches have focused on the epicardial coronary arteries while addressing angina pectoris. Although the importance of the coronary microcirculation in maintaining appropriate myocardial perfusion has been recognized for several decades, the substantial morbidity of coronary microvascular dysfunction (CMD) has not been appreciated until recently. It is not possible to diagnose of microvascular angina clinically with the current knowledge. Resting or exercise electrocardiogram is nondiagnostic. Imaging with speckle tracking in echocardiography may reveal focal diastolic and/or systolic dysfunction. Other noninvasive investigations includes, Contrast stress echocardiography, ${ }^{99}$ Tc-sestamibi imaging cardiovascular magnetic resonance (CMR), Nuclear magnetic resonance spectroscopy may show some degree of abnormality. Invasive methods like intracoronary adenosine and acetylecholine test may guide us to diagnose CMD. No guideline directed medical therapy is still available for the CMD. Risk factors modification like smoking cessation and weight-loss may improve endothelial dysfunction and CMD. Beta blockers, calcium channel blockers, Angiotensin converting enzyme inhibitors and statin are now used in different clinical condition related to microvascular angina. After these medical treatment patient with microvascular angina have higher risk of MACE compared with people without angina. So, physicians must be aware of this potentially fatal but under recognized clinical entity.
\end{abstract}

Key Words: Coronary Microvascular Dysfuction (CMD), Update.

University Heart Journal 2020; 16(1): $43-49$

Introduction:

Coronary angiography is found to be normal in about $30 \%$ of cases who present with chest pain. \& this percentage is even higher in woman ${ }^{1}$. Structural and functional abnormalities of the microcirculation can impair myocardial perfusion which is called coronary microvascular dysfunction and the resulting ischemia is known as microvascular ischaemia ${ }^{2,3}$. Most of the researches have focused on the epicardial coronary arteries while addressing angina pectoris. Although the importance of the coronary microcirculation in maintaining appropriate myocardial perfusion has been recognized for several decades, the substantial morbidity of coronary microvascular dysfunction (CMD) has not been appreciated until recently. Studies have found that CMD itself is associated with higher rates of MACE irrespective of presence of obstructive $\mathrm{CAD}^{4,5,6}$. According to Camici and Crea, CMD are classified CMD into four subtypes: (i) CMD without myocardial diseases and obstructive CAD, (ii) CMD in myocardial diseases, (iii) CMD in obstructive
CAD, and (iv) iatrogenic CMD. The underlying mechanisms of CMD vary according to clinical context and some of them can even overlap. The aim of this article is to provide an update on CMD based on published literature in recent years.

\section{Risk Factors \& Pathophysiology}

CMD is associated with hypertension, dyslipidemia, smoking, insulin resistance \& diabetes and accelerated by early menopause and obesity. CFR is also reduced with aging. Coronary microvascular abnormality are more pronounced in female than male $(66 \% \text { vs. } 60 \%)^{8}$

Although microvascular function appears similar in women and men by Index of microcirculatory resistance (IMR), CFR is lower in women due to higher resting coronary vasomotor tone. ${ }^{8}$

Endothelial dependent and independent coronary vasodilatation are also significantly impaired in chronic 


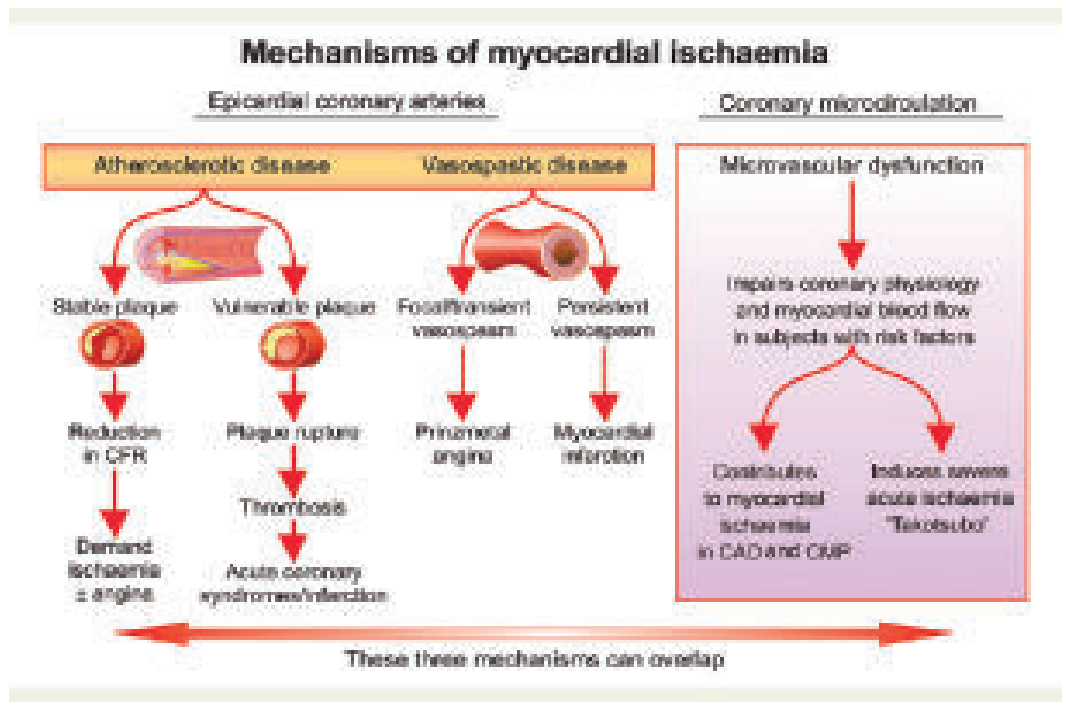

Fig.-1: There are three mechanisms of myocardial ischemia: a) atherosclerotic disease b) vasospastic disease c) coronary microvascular dysfunction (CMD). Like the other two, coronary microvascular dysfunction can cause transient myocardial ischemia as in patients with coronary artery disease (CAD) or cardiomyopathy (CMP) or to severe acute ischemia as observed in Takotsubo syndrome. CFR, coronary flow reserve. ${ }^{7}$

hyperglycemia, insulin resistance and hyperinsulinaemia. ${ }^{9}$ Studies have shown that endothelial dysfunction can be improved by good glycemic control in patients with no obstructive epicardial CAD. ${ }^{10}$

Inflammation also adversely affect coronary microvascular responses as evidenced by raised $\mathrm{C}$-reactive protein in patients with microvascular angina. CMD is also common in patients with systemic lupus erythematosus and rheumatoid arthritis.

In HCM, medial hypertrophy, intimal hyperplasia, and decreased luminal size of the micro vessels cause CMD and myocardial ischemia. ${ }^{11}$

In Takutsobu syndrome, microvascular constriction with subclinical CMD are augmented by endothelial dysfunction. ${ }^{12}$

In myocarditis, chest pain is due to myocarditis induced coronary vasoconstriction and direct infection of endothelial and/ or vascular smooth muscle cells may also contribute.

In aortic stenosis, CFR is adversely affected by reduced diastolic filling time, increased diastolic filling pressure and intramyocardial pressure which ultimately lead to reduced sub-endocardial perfusion, increased intramyocardial systolic pressure, and delayed myocardial relaxation after systole. ${ }^{13,14}$

In infiltrative cardiac diseases like amyloidosis, myocyte hypertrophy and perivascular fibrosis \& endothelial deposits cause MVD \& increased microvascular resistance. ${ }^{15,16}$

CMD may present with obstructive atherosclerotic coronary arteries. Stable IHD patient may share common risk factors for microvascular dysfunction and these may lead to concomitant presence of both. In ACS patient MVO results from the combination of four factors: (i) distal atherothrombotic embolization; (ii) ischaemic injury; (iii) reperfusion injury; and (iv) individual susceptibility of coronary microcirculation to injury.

CMD after PCI occur due to coronary vasoconstriction and embolization of coronary microcirculation \& same phenomenon also happen after coronary artery bypass grafting (CABG). ${ }^{17,18}$ (Figure-2)

\section{Diagnosis}

It is not possible to diagnose of microvascular angina clinically with the current knowledge. Electrocardiogram may show non specific ST T wave change, and exercise electrocardiogram is nondiagnostic. Regional wall motion abnormalities are usually not found in echocardiography. Radio-isotope imaging can detect only severe localized disease. So non-invasive techniques need high index of clinical suspicion to detect CMD. Currently, diagnosis requires presence of normal epicardial coronaries, CFR less than 2.5 on adenosine induced hyperemia, and absence of spasm of epicardial coronaries on acetylcholine challenge test. 


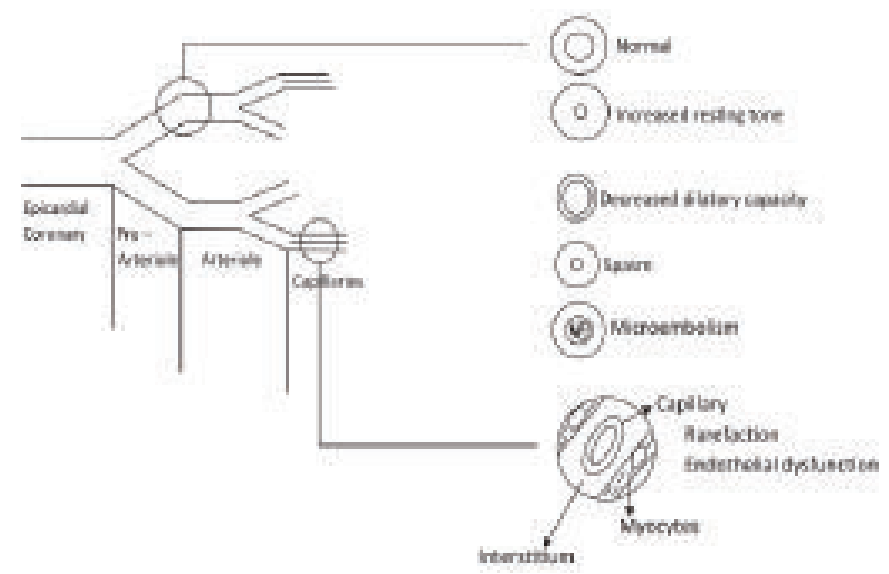

Fig.-2: Pathophysiology of microvascular angina.

\section{Clinical Profile}

Clinically it is very difficult to clearly differentiate microvascular angina from angina that results from isolated epicardial coronary artery disease ${ }^{19,20}$. The clues to suspect CMD are symptoms persistence despite complete revascularization symptoms disproportionate to angiographic findings, poor response to nitroglycerine \& cessation of effort. Patients with microvascular coronary spasm usually have symptoms during night or early morning while at rest. ${ }^{21}$

In cardiac syndrome $\mathrm{Y}$, abnormally high microvascular resistance causes rest angina $\&$ coronary slow flow is usually found. $^{22}$

No research work has been done on angina equivalent. The role of microvascular dysfunction in ST elevation myocardial infarction is also not clear. ${ }^{23}$ Chronic, diffuse, persistent, and progressive coronary microvascular dysfunction can produce global diastolic and/or systolic dysfunction with normal coronary angiogram in DCM patients.

\section{Non-invasive method}

Resting electrocardiogram does not demonstrate significant changes even during chest pain. ${ }^{22}$ In microvascular coronary spasm, borderline ischemic electrocardiogram changes may be found. ${ }^{21}$ Microvascular angina may be suggested by chest pain with ischemic ECG changes without any wall motion abnormality on echocardiography. ${ }^{19}$ Adenosine induced early long axis diastolic dysfunction may be found in tissue Doppler imaging. ${ }^{24}$ Strain rate imaging with speckle tracking may reveal focal diastolic and/or systolic dysfunction. Exercise ECG is usually nonconclusive. ${ }^{19}$ Slow recovery or unsatisfactory response to sublingual nitrates may suggest microvascular dysfunction. ${ }^{25}$ Flow in left anterior descending coronary artery can be assessed by Doppler echocardiography. Coronary flow velocity is measured at baseline and again after adenosine induced maximal hyperemia. Difference is taken as representative of coronary flow reserve (CFR). In absence of epicardial coronary artery disease, increased flow is taken as an indirect marker of dilatation of coronary microvasculature in response to adenosine. Other noninvasive investigations includes, Contrast stress echocardiography, ${ }^{99} \mathrm{Tc}$-sestamibi imaging, cardiovascular magnetic resonance (CMR), Nuclear magnetic resonance spectroscopy. ${ }^{26}$

\section{Invasive methods}

While diagnosing primary microvascular angina, it should be established that epicardial coronary arteries are normal in structure \& function. Acetylcholine and adenosine respectively cause endothelium dependent and endothelium independent vasodilatation of epicardial coronaries. Microvascular dysfunction is often associated with epicardial coronary artery disease. While fractional flow reserve (FFR) determines functional significance of a coronary lesion, corrected thrombolysis in myocardial infarction (TIMI) frame count quantifies coronary blood flow. ${ }^{27}$ Slow flow may be present in case of advanced $\&$ extensive coronary microvascular dysfunction. ${ }^{28}$ It is also present in case of diffuse spasm, increased coronary vasomotor tone or micro embolization. Microcirculation can be assessed qualitatively by Myocardial blushing, though it's sensitivity is low. ${ }^{29}$

Suspected vasospastic angina can be provoked by intracoronary injection of acetylcholine. Appearance of angina and ECG changes without spasm of epicardial coronary artery suggests coronary microvascular spasm. 
But it frequently coexists with spasm of epicardial coronaries. ${ }^{30}$ Right coronary artery is most susceptible to vasospasm. Therefore, assess- ment of coronary microvascular function only in left anterior descending coronary may be insufficient. Index of microcirculatory resistance (IMR) is calculated as distal coronary pressure multiplied by the hyperemic mean transit time. It has got some limitations of it's own.

As none of the diagnostic tests are conclusive of CMD, clinical correlation is of paramount importance for detection of CMD.(Figure-3)

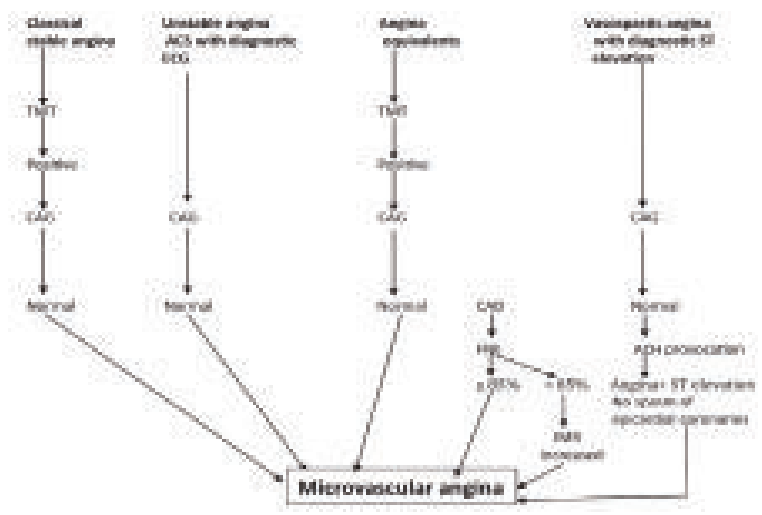

Fig.-3: Diagnostic algorithm. Abbreviations: Ach, acetylcholine; ACS, acute coronary syndrome; CAD, coronary artery disease; CAG, coronary angiography; $I M R$, index of microcirculatory resistance; FFR, fractional flow reserve; TMT, treadmill stress test. ${ }^{7}$

\section{Treatment of Coronary Microvascular Dysfunction}

No guideline directed medical therapy is still available for the CMD. Risk factors modification like smoking cessation and weight-loss may improve endothelial dysfunction and CMD. Perindopril and indapamide for may be prescribed in the absence of myocardial diseases and obstructive coronary artery disease. ${ }^{31}$ Statins and angiotensin converting enzyme (ACE) inhibitors should be present as first line of treatment in MVA. ${ }^{32,33}$ Calcium antagonists do not improve CFR and show inconsistent effects on symptoms, ${ }^{34}$ while beta-blockers appear to reduce chest pain ${ }^{35}$ Ranolazine is also beneficial for MVA. Imipramine may give symptomatic improvement in case of altered cardiac pain perception. (Figure-4)

Finally, spinal cord stimulation ${ }^{36}$ and enhanced external counterpulsation ${ }^{37}$ may be tried in case of refractory angina. Menopausal hormone therapy may improve emotional wellbeing in postmenopausal women with angina and 'normal' angiograms; yet, there is no symptom benefit for this patients. ${ }^{38}$

In HCM, alcohol septal ablation may improve CFR and septalendocardial-to-epicardial MBF. ${ }^{39}$ While drug treatment offers no benefit in enhancing myocardial perfusion. ${ }^{40,41}$

In dilated cardiomyopathy, beta-blockers, ${ }^{42,43}$ but not calcium antagonists or ACE inhibitors likely to improve CMD. ${ }^{44}$ Allopurinol may also have beneficial effect on CMD. ${ }^{45}$

No study is yet to be performed to evaluate the role of any intervention on CMD in acute myocarditis but betablockers \& ivabradine may be helpful by selectively reducing the heart rate $\&$ increasing diastolic filling time. But this theoretical benefit must be translated into clinical trials.

A-ch, acetylcholine test; AFD, Anderson-Fabry's disease; $\mathrm{AS}$, aortic stenosis; $\mathrm{BG}$, blush grade; $\mathrm{CABG}^{`}$, coronary aortic bypass graft; CMD, coronary microvascular dysfunction; CMR, cardiac magnetic resonance; COCM, congestive cardiomyopathy; HCM, hypertrophic cardiomyopathy; MVA, microvascular angina; MVO, microvascular obstruction; PET: positron emission tomography; pPCI, primary percutaneous coronary intervention; PVB, Parvovirus B9; RF, risk factors; STR,

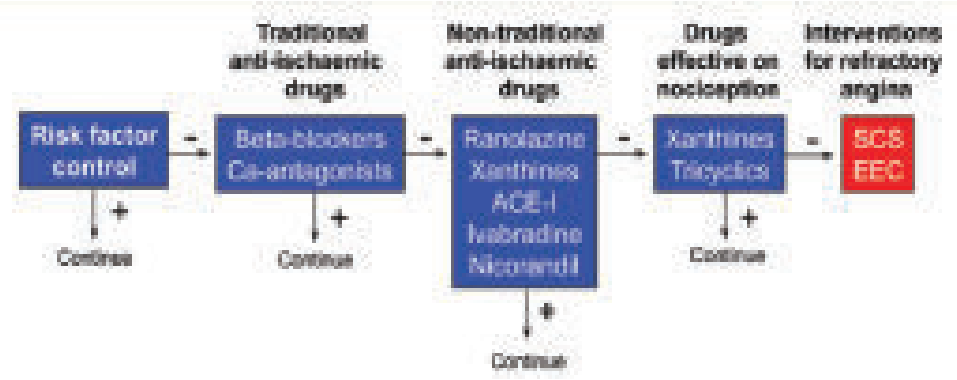

Fig.-4: Treatment algorithm for patients with microvascular angina. SCS, spinal cord stimulation; EEC, enhanced external counterpulsation. ${ }^{7}$ 
Table-I

Diagnosis, prognosis, and treatment of coronary microvascular dysfunction in different clinical scenarios. ${ }^{7}$

\begin{tabular}{|c|c|c|c|c|}
\hline Type of CMD & Specifc diseases & Dagnnods & Inpact on outconse & Treatment \\
\hline Type1 & $\begin{array}{l}\text { RF } \\
\text { MNA }\end{array}$ & $\begin{array}{l}\text { TTLE } \\
\text { TTDE ONR }\end{array}$ & $\begin{array}{l}\text { Ulionow" } \\
\text { Doxinated }\end{array}$ & $\begin{array}{l}\text { Rf contel } \\
\text { RF sorted see Figure } 4\end{array}$ \\
\hline Type? & $\begin{array}{l}\text { HCM } \\
\text { COCM } \\
\text { Pofshyocordits } \\
\text { AFD } \\
\text { Anplobidosis } \\
\text { AS }\end{array}$ & $\begin{array}{l}\text { CMR. PET } \\
\text { CMR, PET } \\
\text { ACh } \\
\text { OMR PET } \\
\text { GMR.PET } \\
\text { OMR. PET }\end{array}$ & 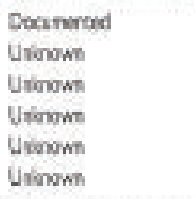 & 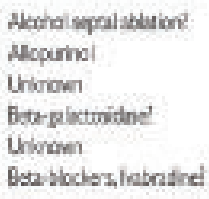 \\
\hline Type 3 & $\begin{array}{l}\text { Sableangirs } \\
\text { MVD firpPC }\end{array}$ & $\begin{array}{l}\text { Arpinasior PQ } \\
\text { BG, STR, CMR }\end{array}$ & $\begin{array}{l}\text { Uxinown } \\
\text { Dexanunded }\end{array}$ & $\begin{array}{l}\text { Angiogeness } \\
\text { Set Fins } 5\end{array}$ \\
\hline Typed & $\begin{array}{l}\text { RO } \\
\text { Crag }\end{array}$ & $\begin{array}{l}\text { Thrix } \\
\text { Thrix }\end{array}$ & $\begin{array}{l}\text { Docinarced } \\
\text { Docinerted }\end{array}$ & $\begin{array}{l}\text { Sraik, alpha-Shackert! } \\
\text { Stank }\end{array}$ \\
\hline
\end{tabular}

ST segment resolution; Tn, troponin; TTDE, transthoracic Doppler echocardiography. It is unknown the incremental prognostic value of coronary microvascular dysfunction in addition to that conveyed by risk factors. ${ }^{7}$

Attempts should be made to promote collateral growth in case of refractory angina which may favorably influence outcome \& symptoms. Therapeutic interventions able to promote collateral growth may have an impact on outcome and also on symptoms. Though gene therapy offered some hope but the results of randomized controlled trials are not promising. Moreover to promote collaterals, intramyocardial administration of progenitor vascular cells should be validated through trials.

In ACS two small randomized studies ${ }^{46}$ found a beneficial effect of manual thrombus aspiration vs. the standard procedure in improving myocardial reperfusion. The concept of intracoronary adenosine administration is promising. Ischemic conditioning, in particular, ischemic post-conditioning ${ }^{47}$ and remote pre conditioning ${ }^{48}$ are also beneficial.

\section{Conclusion:}

Patients with microvascular angina have higher risk of MACE compared with people without angina. Physicians must be aware of this potentially fatal but under recognized clinical entity. Extensive research work should be carried out to identify suitable non-invasive methods for evaluation of microvascular and endothelial function. Now a day's PET, MRI or CT perfusion, and contrast-enhanced Doppler echocardiography is a potential modality. Though till now guideline directed treatment is not available but treatment should address the underlying pathophysiology. So it can be concluded that CMD is a true clinical entity rather than a mystery or an academic curiosity.

\section{References:}

1. Adrián I. Löffler, MDa and Jamieson Bourque, MD, MHS* Coronary Microvascular Dysfunction, Microvascular Angina, and Management. Curr Cardiol Rep. 2016; 18(1): 1.

2. de Silva, R. and P.G. Camici, Role of positron emission tomography in the investigation of human coronary circulatory function. Cardiovasc Res, 1994. 28(11): p. 1595612.

3. Camici, P.G. and F. Crea, Coronary microvascular dysfunction. N Engl J Med, 2007. 356(8): p. 830-40.

4. Murthy VL, Naya M, Foster CR, et al. Improved cardiac risk assessment with noninvasive measures of coronary flow reserve. Circulation. 2011; 124:2215-24. [PubMed: 22007073]

5. Pepine CJ, Anderson RD, Sharaf BL, et al. Coronary microvascular reactivity to adenosine predicts adverse outcome in women evaluated for suspected ischemia: Results from the national heart, lung and blood institute. WISE (women's ischemia syndrome evaluation) study. J Am Coll Cardiol. 2010; 55:2825-32. [PubMed: 20579539]

6. Fukushima K, Javadi MS, Higuchi T, et al. Prediction of shortterm cardiovascular events using quantification of global myocardial flow reserve in patients referred for clinical $82 \mathrm{Rb}$ PET perfusion imaging. Journal of Nuclear Medicine. 2011; 52:726-32. [PubMed: 21498538]

7. Crea F, Camici PG, Merz CNB, Coronary microvascular dysfunction: an update. European Heart Journal 2014; 35: 1101-11

8. Taqueti VR, Hachamovitch R, Murthy VL, et al. Global coronary flow reserve is associated with adverse cardiovascular events independently of luminal angiographic severity and modifies the effect of early revascularization. Circulation. 2015; 131:19-27. [PubMed: 25400060]

9. Sara JD, Widmer RJ, Matsuzawa Y, Lennon RJ, Lerman LO, Lerman A. Prevalence of Coronary Microvascular Dysfunction Among Patients With Chest Pain and Nonobstructive Coronary Artery Disease. JACC Cardiovasc Interv. 2015 Sep;8(11):1445-53. 
10. Jadhav, S., et al., Effects of metformin on microvascular function and exercise tolerance in women with angina and normal coronary arteries: a randomized, double-blind, placebocontrolled study. J Am Coll Cardiol, 2006. 48(5): p. 956-63.

11. Camici PG, Crea F. Coronary microvascular dysfunction. N Engl J Med 2007;356:830-840.

12. Crea F, Camici PG, Bairey Merz CN. Coronarymicrovasculardysfunction: an update.Eur Heart J. 2014 May;35(17):1101-11.

13. Marcus, M.L., et al., Decreased coronary reserve: a mechanism for angina pectoris in patients with aortic stenosis and normal coronary arteries. N Eng1 J Med, 1982. 307(22): p. 1362-6.

14. Dunn, R.B. and D.M. Griggs, Jr., Ventricular filling pressure as a determinant of coronary blood flow during ischemia. Am J Physiol, 1983. 244(3): p. H429-36.

15. Elliott, P.M., et al., Coronary microvascular dysfunction in male patients with Anderson-Fabry disease and the effect of treatment with alpha galactosidase A. Heart, 2006. 92(3): p. 357-60.

16. Eng, C.M., et al., Safety and efficacy of recombinant human alpha-galactosidase A-replacement therapy in Fabry's disease. N Engl J Med, 2001. 345(1): p. 9-16.

17. el-Tamimi, H., et al., Inappropriate constriction of small coronary vessels as a possible cause of a positive exercise test early after successful coronary angioplasty. Circulation, 1991. 84(6): p. 2307-12.

18. Spyrou, N., et al., Persistent but reversible coronary microvascular dysfunction after bypass grafting. Am J Physiol Heart Circ Physiol, 2000. 279(6): p. H2634-40.

19. Lanza GA, Crea F. Primary coronary microvascular dysfunction: clinical presentation, pathophysiology and management. Circulation. 2010;121:2317-25.

20. Kothawade K, Merz NB. Microvascular coronary dysfunction in women: pathophysiology, diagnosis management. Curr Probl Cardiol. 2011;36:291-318.

21. Ohba K, Sugiyama S, Sumida H, et al. Microvascular coronary artery spasm presents distinctive clinical features with endothelial dysfunction as non obstructive coronary disease. J Am Heart Assoc. 2012;1:E0002485.

22. Hurst $\mathrm{T}$, Olson $\mathrm{T}$, Olson $\mathrm{L}$, et al. Cardiac syndrome $\mathrm{X}$ and endothelial dysfunction: new concepts in prognosis and treatment. Am J Med. 2006;119:560-6.

23. Lerman A, Holmes DR, Herrmann J, et al. Microcirculatory dysfunction in ST elevation myocardial infarction: cause, consequence or both? Eur Heart J. 2007;28:788-97.

24. Vinereanu D, Fraser AG, Robinson M, Lee A, Tweddel A. Adenosine provokes diastolic dysfunction in microvascular angina. Postgrad Med J. 2002;78:40-2.

25. Lanza GA, Manzoli A, Bia E, et al. Acute effects of nitrates on exercise testing in patients with syndrome X. Circulation. 1994;90:2695-2700.

26. Buchthal SD, den Hollander JA, Bairey-Merz CN, et al. Abnormal myocardial phosphorus - 31 nuclear magnet resonance spectroscopy in women with chest pain but normal coronary angiograms. N Eng J Med. 2000;342:829-35.

27. Gibson CM, Cannon CP, Daley WL, et al. TIMI frame count: a quantitative method of assessing coronary artery flow. Circulation. 1996;93:879-88.

28. Bettrame JF, Limaye SB, Wuttke RD, et al. Coronary hemodynamic and metabolic studies of the coronary slow flow phenomenon. Am Heart J. 2003;146:84-90.

29. Vant Hof AW, Liem A, Suryapranata H, et al. Angiographic assessment of myocardial reperfusion in patients treated with primary angioplasty for acute myocardial infarction: myocardial blush grade. Jwolle Myocardial Infarction study group. Circulation. 1998;97:2302-2306.

30. Teragawa H, Mitsuba N, Ishibashi K, et al. Evaluation of coronary microvascular function in patients with vasospastic angina. World J Cardiol. 2013;5:1-7.

31. Neglia D, Fommei E, Varela-Carver A, Mancini M, Ghione S, Lombardi $\mathrm{M}$, et al. Treatment of hypertension with perindopril plus indapamide leads to reverse coronary microvascular remodelling and improved blood flow. J Hypertens 2011;29:364-72.

32. Kayikcioglu M, Payzin S, Yavuzgil O, Kultursay H, Can LH, Soydan I. Benefits of statin treatment in cardiac syndromeX. Eur Heart J 2003;24:1999-2005.

33. Chen JW, HsuNW, Wu TC, Lin SJ, Chang MS. Long-term angiotensin-converting enzyme inhibition reduces plasma asymmetric dimethylarginine and improves endothelial nitric oxide bioavailability and coronary microvascular function in patients with syndrome x. Am J Cardiol 2002;90:974-82.

34. Sutsch G, Oechslin E, Mayer I, Hess OM. Effect of diltiazem on coronary flow reserve in patients with microvascular angina. Int J Cardiol 1995;52:135-43.

35. Lanza GA, Colonna G, Pasceri V, Maseri A. Atenolol versus amlodipine versus isosorbide-5-mononitrate on anginal symptoms in syndrome X. Am J Cardiol 1999;84:854-56

36. Sgueglia GA, Sestito A, Spinelli A, Cioni B, Infusino F, Papacci $\mathrm{F}$ et al. Long-term follow-up of patients with cardiac syndrome X treated by spinal cord stimulation. Heart 2007;93:591-97.

37. Kronhaus KD, Lawson WE. Enhanced external counterpulsation is an effective treatment for Syndrome X. Int J Cardiol 2009;135:256-257.

38. Adamson DL,Webb CM, Collins P. Esterified estrogens combined with methyltestosterone improve emotional wellbeing in postmenopausal women with chest pain and normal coronary angiograms. Menopause 2001;8:233-8.

39. Jaber WA, Yang EH, Nishimura RA, Sorajja P, Rihal CS, Elesber $A$, et al. Immediate improvement in coronary flow reserve after alcohol septal ablation in patients with hypertrophic obstructive cardiomyopathy. Heart 2009; 95:564-9.

40. Choudhury L, Elliott P, Rimoldi O, Ryan M, Lammertsma AA, Boyd H, et al. Transmural myocardial blood flow distribution in hypertrophic cardiomyopathy and effect of treatment. Basic Res Cardiol 1999;94:49-59. 
41. Gistri R, Cecchi F, Choudhury L, Montereggi A, Sorace O, Salvadori PA, et al. Effect of verapamil on absolute myocardial blood flow in hypertrophic cardiomyopathy. Am J Cardiol 1994;74:363-8.

42. Erdogan D, Gullu H, Caliskan M, Ciftci O, Baycan S, Yildirir A, Et al. Nebivolol improves coronary flow reserve in patients with idiopathic dilated cardiomyopathy. Heart 2007;93: 319-24.

43. FanY, Lin JH, DongG, ZhuJ, Yin F, Yang SS. The effect of carvedilol oncoronary flow reserve in patients with dilated cardiomyopathy. Zhonghua Nei Ke Za Zhi 2010;49:217-9.

44. Neglia D, Sambuceti G, Giorgetti A, Bartoli M, Salvadori P, Sorace O, et al. Effects of long-term treatment with verapamil on left ventricular function and myocardial blood flow in patients with dilated cardiomyopathy without overt heart failure. J Cardiovasc Pharmacol 2000;36:744-50.
45. Erdogan D, Tayyar S, Uysal BA, Icli A, Karabacak M, Ozaydin $\mathrm{M}$, et al. Effects of allopurinol on coronary microvascular and left ventricular function in patients with idiopathic dilated cardiomyopathy. Can J Cardiol 2012;28:721-7.

46. Silva-Orrego P, Colombo P, Bigi R, Gregori D, Delgado A, Salvade $\mathrm{P}$, et al. Thrombus aspiration before primary angioplasty improves myocardial reperfusion in acute myocardial infarction: the DEAR-MI (Dethrombosis to Enhance Acute Reperfusion in Myocardial Infarction) study. J Am Coll Cardiol 2006;48:1552-9.

47. Thibault H, Piot C, Staat P, Bontemps L, Sportouch C, Rioufol $\mathrm{G}$, et al. Long term benefit of postconditioning. Circulation 2008;117:1037-44.

48. Bøtker HE, Kharbanda R, Schmidt MR, Bøttcher M, Kaltoft $\mathrm{AK}$, Terkelsen CJ,Munk $\mathrm{K}$, et al. Remote ischaemic conditioning before hospital admission, as a complement to angioplasty, and effect on myocardial salvage in patients with acute myocardial infarction: a randomised trial. Lancet 2010;375:727-34. 